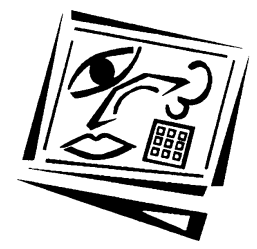

\title{
Using dynamic geometry software to improve eight grade students' understanding of transformation geometry
}

\author{
Bulent Guven \\ Karadeniz Technical University
}

\begin{abstract}
This study examines the effect of dynamic geometry software (DGS) on students' learning of transformation geometry. A pre- and post-test quasi-experimental design was used. Participants in the study were 68 eighth grade students (36 in the experimental group and 32 in the control group). While the experimental group students were studying the transformation geometry in a (DGE), the same instruction was carried out with dotted and isometric worksheets with the control group students. A 15 multiple choice Transformation Geometry Achievement Test and a 15 open ended item Learning Levels of Transformation Geometry Test were used as pre and post-test. The result of covariance analysis showed that the experimental group outperformed the control group not only in academic achievement but also in levels of learning of transformation geometry.
\end{abstract}

\section{Introduction}

As a result of dramatic changes in mathematics education around the world, in Turkey both elementary and secondary school mathematics curricula have changed in the light of new mandates since 2005. Previous curricula were under the hegemony of a set of facts, formulas and procedures. Current curricula focus on the processes of exploration, communication and conceptualisation through the classroom activities rather than presenting a plethora of facts in traditional ways. The aim of the reform is to establish inquiry mathematics. In contrast with traditional classroom activities that emphasise repetition, practice, and other routinised means to reach some focused endpoint, inquiry mathematics instruction emphasises student engagement in situated mathematical problem-solving (Guven et al., 2009).

Recently, computer technology has emerged as a tool facilitating an important paradigm in the development of mathematics curricula, suggesting its effectiveness for accomplishing new demands in education (Sinclair, Renshaw \& Taylor, 2004; NCTM, 2000). Accordingly, the use of computers in mathematics instruction has become a basic element in the Turkish educational system, not as a standalone resource but as an integral part of the teaching/ learning environment. The use of dynamic geometry software (DGS) and computer algebra systems has been especially emphasised as an important catalyst for achieving desired objectives. Technology classes found in almost all schools are the first steps.

\section{Dynamic geometry software}

Since the 1990s, the contribution of technology to the teaching and learning of geometry has been perceived mainly as strongly linked with dynamically manipulable, 
interactive geometry software, such as Cabri and Geometer's Sketchpad. The "dragging" feature of DGS distinguishes it from other geometry software (Botana \& Valcarce, 2003). Once a construction is completed, the user can drag certain elements of it, and the whole construction behaves in such a way that specified constraints are maintained, providing an environment in which students can experiment freely. They can easily test their intuitions and conjectures in the process of looking for patterns and checking the invariant properties of figures (Marrades \& Gutierrez, 2000). Luthuli (1996) characterised this type of instruction as research-based geometry. Because specific instances can be varied easily by dragging, with results visible on the computer screen, attention has tended to be focused on the software's potential in aiding the transition from particular to general cases (Hoyles \& Jones, 1998). This inductive nature of the software gives students an opportunity to learn Euclidean geometry via explorations that promote the conjecturing process (Stols \& Kriek, 2011). DGS has been regularly used worldwide for teaching and learning Euclidean geometry for a long time. One of the learning fields in which this software is used efficiently is transformation geometry, which is an important sub-learning area of the geometry strand. DGS allows certain affine transformations (translations, reflections, rotations, dilations) to act on figures or their parts. The role of DGS to understand the transformations is stated by NCTM as follows:

\begin{abstract}
Dynamic geometry software allows students to visualize a transformation by manipulating a shape and observing the effect of each manipulation on its image. By focusing on the positions, side lengths, and angle measures of the original and resulting figures, middle-grades students can gain new insights into congruence. Transformations can become an object of study in their own right. Teachers can ask students to visualize and describe the relationship among lines of reflection, centers of rotation, and positions of preimages and images. Using the interactive figure, students might see that the result of a reflection is the same distance from the line of reflection as the original shape. (NCTM, 2000)
\end{abstract}

In a dynamic geometry environment (DGE), transformations can be determined by dynamic data, such as a rotation by moveable angle. These features help students understand transformation geometry dynamically.

Some research studies investigated the effect of DGS on students' achievement in different geometry subjects. McCoy (1991) examined the effect of Geometric Supposer on students' ability to solve high-level problems, low-level problems and application problems by designing an experimental study. The results showed that the scores of students in experimental groups were significantly higher on the high-level and application problems, although there were no significant differences on scores for lowlevel problems. Erbas and Yenmez (2011) designed an experimental study to investigate the effect of using the Geometer's Sketchpad with open-ended investigations of sixth grade students' learning in polygons and congruency and similarity of polygons. The results showed that the treatment created substantial improvement in students' achievement in the experimental group compared with students in the control group. Furthermore, some studies have indicated a positive effect of using dynamic geometry on students' problem solving and posing (Christou et al., 2005), and discovering and conjecturing (Aarnes \& Knudtzon 2003; Habre 2009).

\title{
Geometric transformations
}

While there are many different kinds of geometric transformations, the focus of this study is the concept of geometrical transformations encompassing the three 
transformations (translation, reflection, and rotation) of the plane. According to NCTM (2000), "Instructional programs from pre-kindergarten through grade 12 should enable students to apply transformations and use symmetry to analyze mathematical situations." (p.41).

According to Hollebrands (2003), there are three important reasons to study geometric transformations in school mathematics: it provides opportunities for students to think about important mathematical concepts (e.g., functions, symmetry), it provides a context within which students can view mathematics as an interconnected discipline, and it provides opportunities for students to engage in higher-level reasoning activities using a variety of representations. Lauding its dynamic nature, Peterson (1973) pointed out that transformation geometry encourages students to investigate geometric ideas through an informal and intuitive approach. This approach stresses sensitivity, conjecturing, transformation and inquisitiveness. Transformation can lead students to exploration of the abstract mathematical concepts of congruence, symmetry, similarity, and parallelism; enrich students' geometrical experience, thought and imagination; and thereby enhance their spatial abilities.

Research suggests that students should have a sufficient knowledge of geometric transformations by the end of eighth grade in order to be successful in higher level mathematics studies (Carraher \& Schlieman, 2007; NCTM, 2000). For these reasons there is significant support for the incorporation of geometric transformations in a school geometry courses (Hollebrands, 2003). However, studies showed that students have difficulties in understanding the concepts and variations in performing and identifiying transformations including translation, reflection, rotation and combinations of transformations of these types (Clements \& Burns, 2000; Edwards, 1990; Olson, Zenigami \& Okazaki, 2008; Rollick, 2009). For example, Edwards (1989), found that middle school students encounter difficulties in both executing and identifying transformations. Execution errors including drawing images of reflections in the wrong orientation and out of scale. In these studies, it was concluded that whilst most students have an operational understanding of transformations, most have not developed a conceptual understanding. Some researchers (e.g. Edwards, 1989) have seen dynamic representations as a powerful tool to improve students' understanding from operational to conceptual.

\section{Geometric transformations in Turkish elementary mathematics curriculum}

The first five years of the Turkish elementary mathematics education curriculum comprises four basic strands: Numbers, Geometry, Measurement and Data. In the geometry strand, students gradually learn basic transformations as a sub-learning domain from the second to the eighth grade. In other words, transformation geometry subjects are not packed into one year but spread over seven grades. First, second grade students learn to explain symmetry by using the modals around a straight line. Third grade students learn to determine whether or not a given shape has a symmetry line by folding and to generate symmetric shapes themselves, while fourth grade students learn to determine the symmetry lines of plane shapes without folding. In the fifth grade, students learn to determine the symmetry lines of polygons and to draw a given plane shape's symmetry according to the symmetry line. The modals used in activity samples related to each grade in the curriculum are shown in Table 1. 
Table 1: Samples related to transformation geometry in the Turkish mathematics education curriculum, grades 2-5.

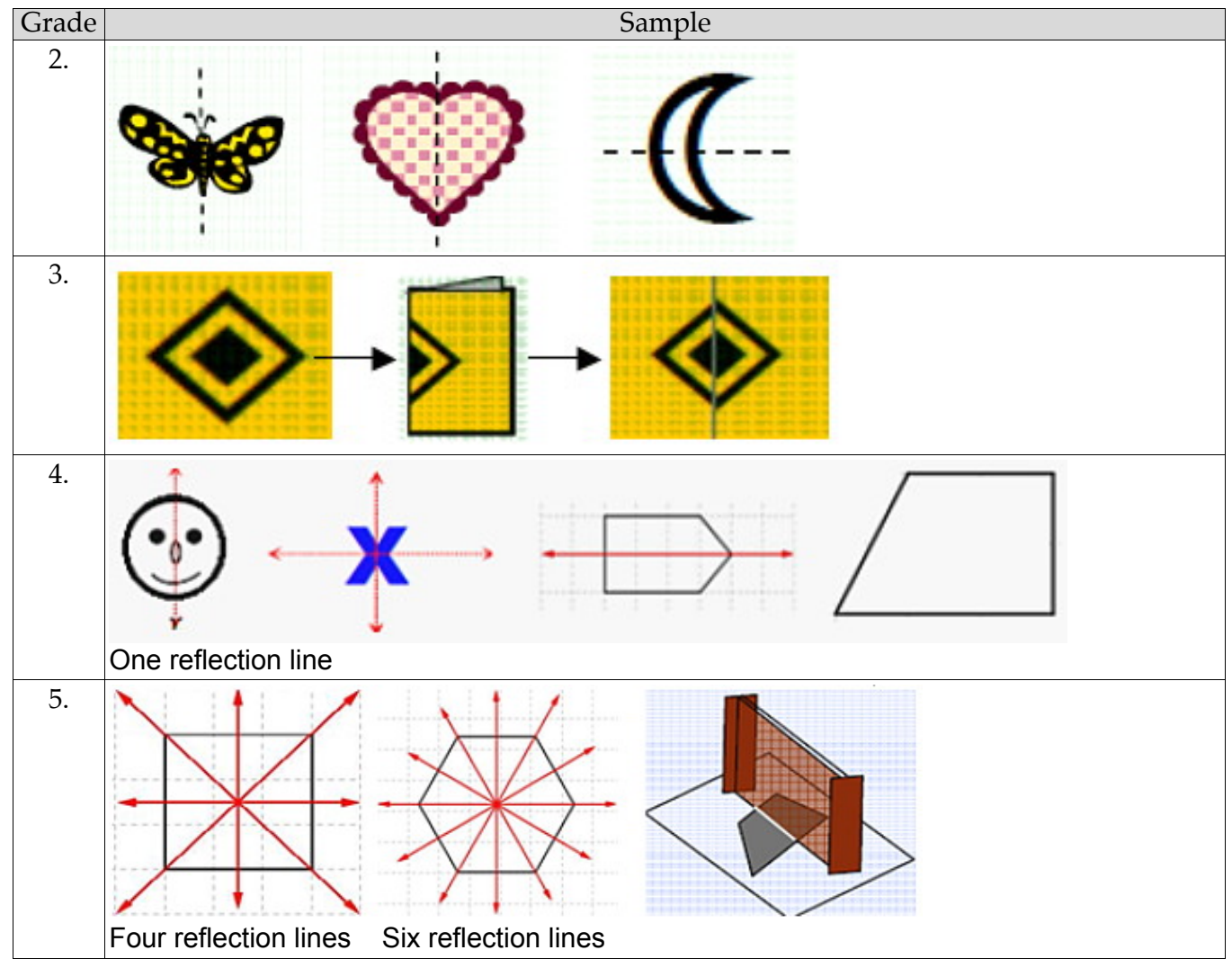

The Turkish elementary mathematics education curriculum guide for the first five grades presents the structure of transformation geometry instruction as follows:

Beginning from the 2nd grade symmetry as a sub-learning domain is brought into program with pursuing a certain development. Appropriate environments for students to differentiate the symmetry and axis of symmetry on concrete models by folding and cutting activities should be provided. In the 4th and 5th grades, that geometric shapes may have more than one axis of symmetry is to be handled for a while after the students have reached a certain levels. (TTKB, 2004, p.29)

As can be seen, although the basics of transformation geometry are included in the 1-5 elementary mathematics education curriculum, a complete formal beginning is not. Also, at these levels teachers are not supposed to make use of DGS while they are explaining the concepts of transformation geometry.

The 6-8 grade elementary mathematics education curriculum consists of five basic strands: Numbers, Geometry, Measurement, Probability and statistics, and Algebra. In the geometry strand, concepts of transformation geometry are taught formally and in detail from the sixth through eighth grades. In this context, sixth grade students learn to explain translation and construct the image of a shape that is formed as the result of translation. Seventh grade students learn to explain reflection and rotation and to draw 
the rotation of shapes around a dot in a line according to an angle that is stated. In the eighth grade, students learn to make composite transformations and to associate the transformations that they have made along an analytical line with coordinates. Models used in activity samples for each grade in the 6-8 elementary mathematics education curriculum are presented in Table 2.

Table 2: The samples that are related to transformation geometry in Turkish grades 6-8 mathematics curriculum

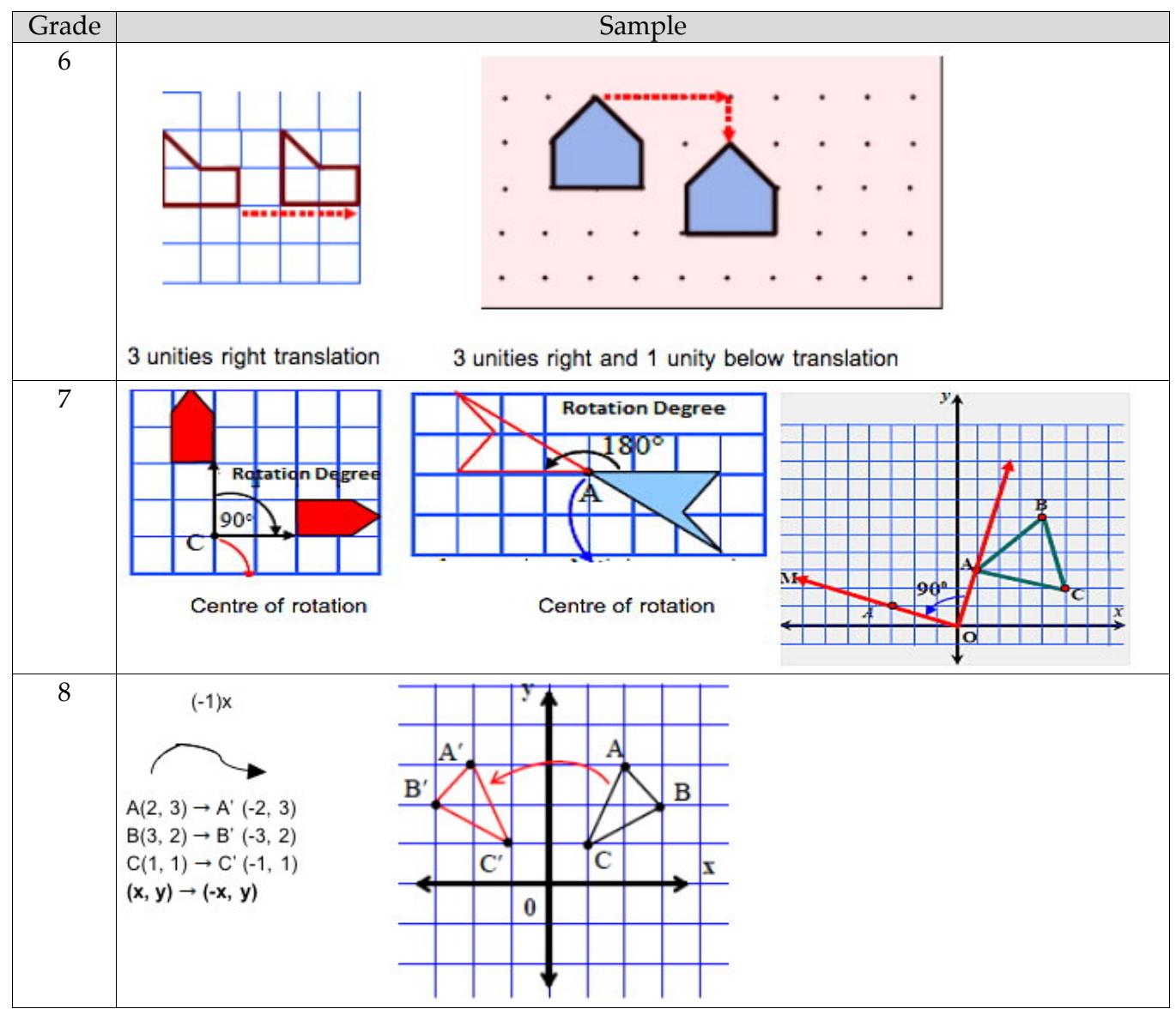

As can be seen, students learn the basic transformations formally between the sixth through eighth grades. Also the curriculum guide recommends that teachers make use of DGS during the teaching of transformation geometry subjects. However, research has shown that the teachers have not been using this software in their classes (Guven et al., 2009).

\section{Learning transformation geometry in a computer environment}

Only a few research studies have examined students' understanding of geometric transformations while using technology (Edwards, 1992, 1997; Edwards \& Zazkis, 1993; Johnson-Gentile, Clements \& Battista, 1994). These studies have utilised Logo 
programming language and DGE. Edwards (1992), introduced twelve middle school students to translations, reflections and dilations in a Logo environment and concluded that it could be used successfully to help students view translations, reflections, and rotations as objects themselves, and the Logo geometry environment could help students to construct concepts of transformation geometry. Johnson-Gentile et al. (1994) compared data on fifth and sixth grade students' learning of transformation geometry in Logo and non-Logo environments and concluded that the Logo treatment students were more likely than the non-Logo treatment students to discuss the transformations instead of the figures to which the transformations were applied.

These early studies provide evidence that teaching geometric transformations to students in a technological environment is feasible and may have positive effects on students' learning of mathematics. Moreover, these early studies did not have the advantage of more sophisticated computing tools that are now available (Hollebrands, 2003). The software programs that were used in these studies were static in nature.

The impact of DGS on students' learning of transformation geometry has been investigated mostly with secondary students and teacher trainees. Some support for the potential of DGE is found in the experimental work of Dixon (1997), who found that dynamic geometry group students were more successful than students in a control group, at identifying and applying reflections and rotations. Hollebrands (2003) investigated the nature of secondary students' understanding of geometric transformations, which included translations, reflections and rotations, in the context of DGE. Students' conceptions of transformations as functions were analysed using the APOS theory (Action-Process-Object, Schema, an extension of Piaget's theory of reflective abstraction applied to the learning of mathematics). The findings showed that while initially all students appeared to reason about transformations as motions, which may have been connected to reasoning about drawings and an action conception, an essential understanding in students' movement toward reasoning about transformations as functions was their understanding of domain.

Harper (2002) investigated four pre-service elementary school teachers' knowledge about geometric transformations in DGE. The major findings were that the participants' vocabulary become more sophisticated, incorporating formal mathematical terminology; all participants were able to construct the reflected image of a figure and a line of reflection based on the properties of reflections; participants were more knowledgeable with the use of a vector to represent a translation's direction and magnitude; participants were able to identify the centre and angle of a single rotation to map a figure with its rotated image; and the DGS provision of immediate visual feedback helped the participants to conjecture, test and revise their solutions.

\section{Theoretical framework}

In the 1950s, two Dutch educators, Dina and Pierre van Hiele, developed a structure for reasoning that they suggested may reflect how children learn geometry. According to the van Hieles, the learner, assisted by appropriate instructional experiences, passes through the following five levels, each of which depends on successful achievement of the previous levels (Fuys, Geddes \& Tischler, 1988): 
Level 1: Recognition

Level 2: Analysis

Level 3: Pre-deductive

Level 4: Deductive

Level 5: Rigour
The student recognises geometric figures by their global appearance, identifies names of figures, but does not explicitly identify their properties.

The student analyses figures in terms of their components and properties, discovers properties and rules of a class of shapes empirically, but does not explicitly interrelate figures or properties.

The student logically interrelates previously discovered properties and rules by giving or following informal arguments.

The student proves theorems deductively, develops sequences of statements to deduce one statement from another, but does not yet recognise the need for rigour.

The student establishes theorems in different axiomatic systems and analyses and compares these systems.

Crowley (1987) described the distinctive characteristics of the five levels of the van Hiele model as follows: (1) The model is sequential in that a learner cannot function at a higher level without first progressing through the thought processes of all previous levels; (2) progress from one level to the next is not through biological development but rather depends on instruction; (3) the linguistic symbols of each level are unique, that is, each level is regarded as having its own language, and learners on different levels cannot understand one another; (4) the intrinsic characteristics of one level become the extrinsic objects of study of the next; and (5) the mismatch between the level of instruction and the level at which a student is functioning may restrict the desired progress.

Similarly, Soon (1989) determined van Hiele-like levels for learning in transformation geometry. The characteristics of these levels are shown in Table 3.

Table 3: Levels of understanding in transformation geometry

\begin{tabular}{|c|c|}
\hline Levels & Characteristics: The student ... \\
\hline Level 1 & $\begin{array}{l}\text { - identifies transformation by the changes in the figure; (a) in simple drawings of } \\
\text { figures and images; and (b) in pictures of everyday applications. } \\
\text { - identifies transformation by performing actual motion; names, discriminates the } \\
\text { transformation. } \\
\text { - names or labels transformations using standard and / or non-standard names and } \\
\text { labels appropriately. } \\
\text { - solves problems by operating on changes of figures or motion rather than using } \\
\text { properties of the changes. }\end{array}$ \\
\hline Level 2 & $\begin{array}{l}\text { - uses the properties of changes to draw the pre-image or image of a given } \\
\text { transformation. } \\
\text { - discovers properties of changes to figures resulting from specific transformation. } \\
\text { - is able to locate axis of reflection, centre of rotation, translation vector and centre of } \\
\text { enlargement. } \\
\text { - relates transformations using coordinates. } \\
\text { - solves problems using known properties of transformations. }\end{array}$ \\
\hline
\end{tabular}




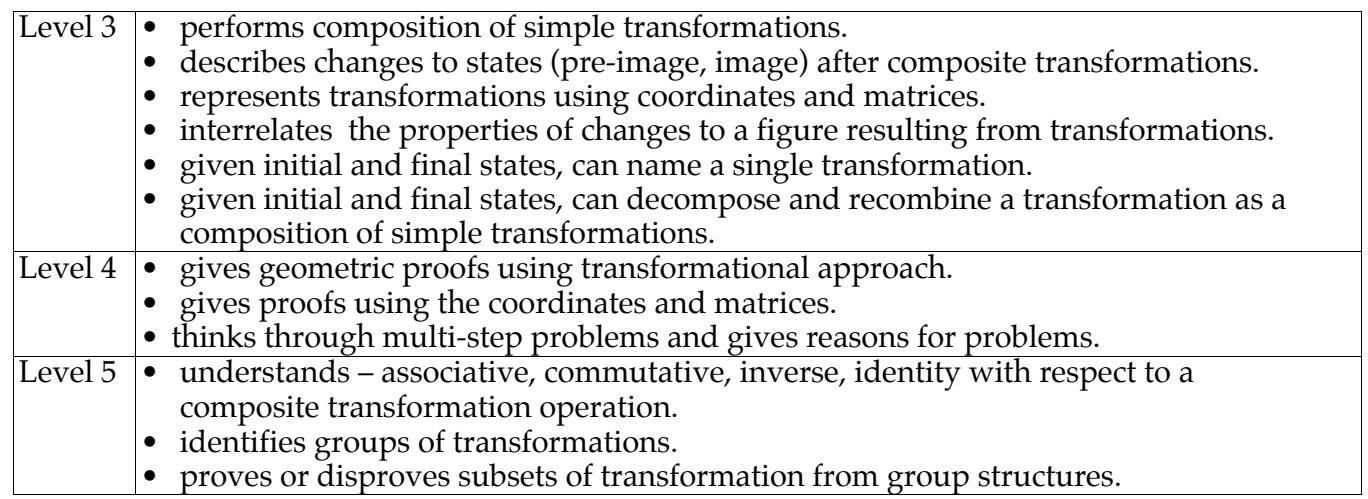

Soon (1989), after diagnosing the levels and applying a Guttman Scologram analysis, indicated that they have a hierarchical structure. As it can be seen in Table 3, levels 4 and 5 are well above the expected performance level of elementary school students. Accordingly, only the first three levels are relevant in the present study, which was carried out with elementary school students.

\section{Purpose of the study}

Battista (2007), in his review about the geometric thinking, highlighted that qualitative research results have already revealed that superior geometry learning can occur with the use of DGS; however, quantitative research results are needed to generalise these results and determine whether using DGEs is "better" than using traditional paper and pencil methods (p.884). Similarly, we don't have enough quantitative evidence for using DGS for geometric transformation subjects. Thus, the purpose of this study is to determine the effect of the DGS Cabri (http://www.cabri.com/, Turkish language version) on eighth grade students' academic achievement and levels of understanding in transformation geometry. More specifically, the research question of the study was as follow: What is the effect of using DGS on eight grade students' academic achievement and levels of understanding of geometric transformations compared to paper and pencil methods?

\section{Method}

\section{Participants}

The participants in the study were 68 eighth grade students ranging in age from 14 to 15 years, from two different classes of a transformation geometry course in a school located in Trabzon, Turkey. There were 36 students ( 21 boys and 15 girls) in the experimental group, a class which was taught using DGS, and 32 students (17 boys and 15 girls) in the control group, which was taught using isometric and dotted worksheets. Purposive sampling was used to situate the study in a school that was well equipped in terms of computer laboratories and technological devices.

The study was carried out during the spring semester of the 2008/2009 academic year. The classes were randomly assigned as either experimental or control groups. Although they were eighth grade students, both classes studied all the transformations taught in the sixth through eighth grades. 


\section{Instruments}

The Transformation Geometry Achievement Test (TGAT) and the Learning Levels of Transformation Geometry Test (LLTGT) were used as data collection instruments in this study.

\section{Transformation Geometry Achievement Test (TGAT)}

This multiple choice geometry achievement test, initially consisting of 20 questions covering translation, rotation and symmetry, was designed by the researchers to measure students' learning of transformation geometry. The test was based on the student text books and teacher guides for sixth, seventh and eighth grades distributed by the Ministry of National Education. The researchers designed the test taking into account student levels, student achievement in the pre-transformation learning domain, and the aims of the study. The completed questions were then examined by two teachers with more than ten years' experience and revised in accordance with their feedback. In its final version, the test was administered as a pre- and post-test before and after the study.

A pilot study using the TGAT was conducted in Autumn 2008, with 53 eighth graders in the same school. As a result of reliability analyses made after pilot applications, 5 items with low reliabilities were removed from the TGAT. However, care was taken to not disrupt content validity. The Spearman-Brown reliability coefficient of the final form was $r=0.81$. Three of the questions covered translation, four covered rotation, four covered symmetry, and the rest covered composite transformations. Sample questions for each transformation are shown in Table 4.

In order to determine students' levels of understanding in transformation geometry, an open ended test which Soon (1989) had developed during his doctoral studies at Florida University was used. The original version of the test includes four questions at the first level, ten questions at the second level, nine questions at the third level and eight questions at the fourth level. Because the students in the sample were eighth grade students, the fourth and fifth levels of this test were not included in our study. Also, in keeping with the Turkish Mathematics education curriculum, the test was revised to include five questions in each level, which involved removing some questions in the second and third levels and adding a new question to the first. A pilot study was conducted to evaluate the effectiveness of this open ended test in determining students' learning of transformation geometry. In pilot study, the test was administered to twelve eighth grade students, chosen by the researchers to represent different levels, at the end of the learning period. Two weeks later, clinical interviews with the same questions were conducted with the same students, whose levels were determined according to the results of the interviews. Over the course of clinical interviews, questions were presented to learners and learners were asked to think aloud while solving the problems. The researcher directed new questions to learners regarding the solution when deemed to be necessary. Questions directed to learners were shaped especially around the question "why". By this means, mathematical process behind the action carried out by the learner was tried to be revealed. These two sets of results were compared and it was found that 10 of the 12 students' clinical interview results were consistent with their open ended test results, indicating that this $15-i t e m$ open ended data collection instrument could be used with $83 \%$ reliability. The LLTGT was also used as a pre- and post-test in the study. Samples of the open ended questions which were used in this test are shown in Table 5. 
Table 4: Some of the items in TGAT

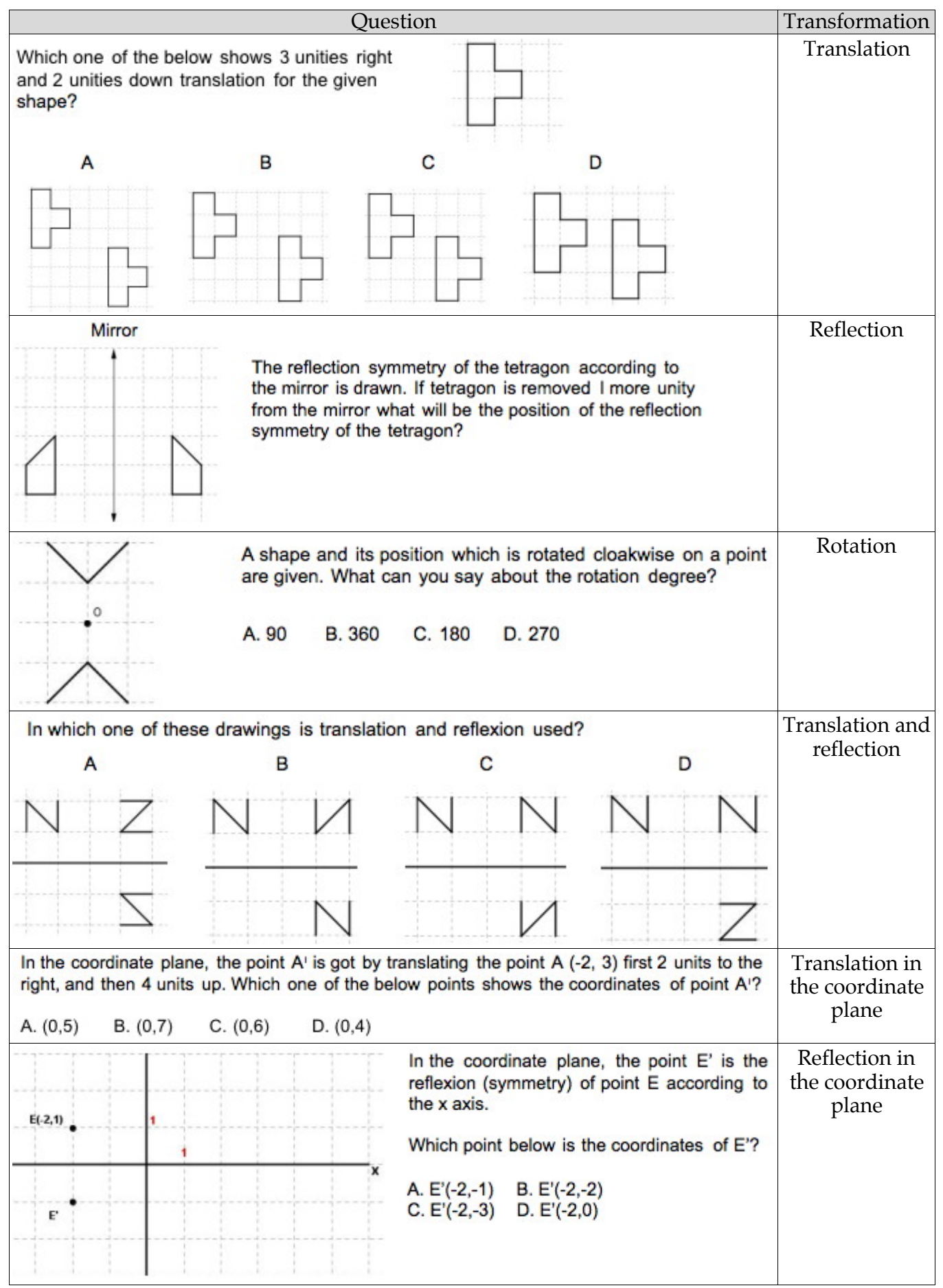


Table 5: Sample questions for each levels of LLTGT

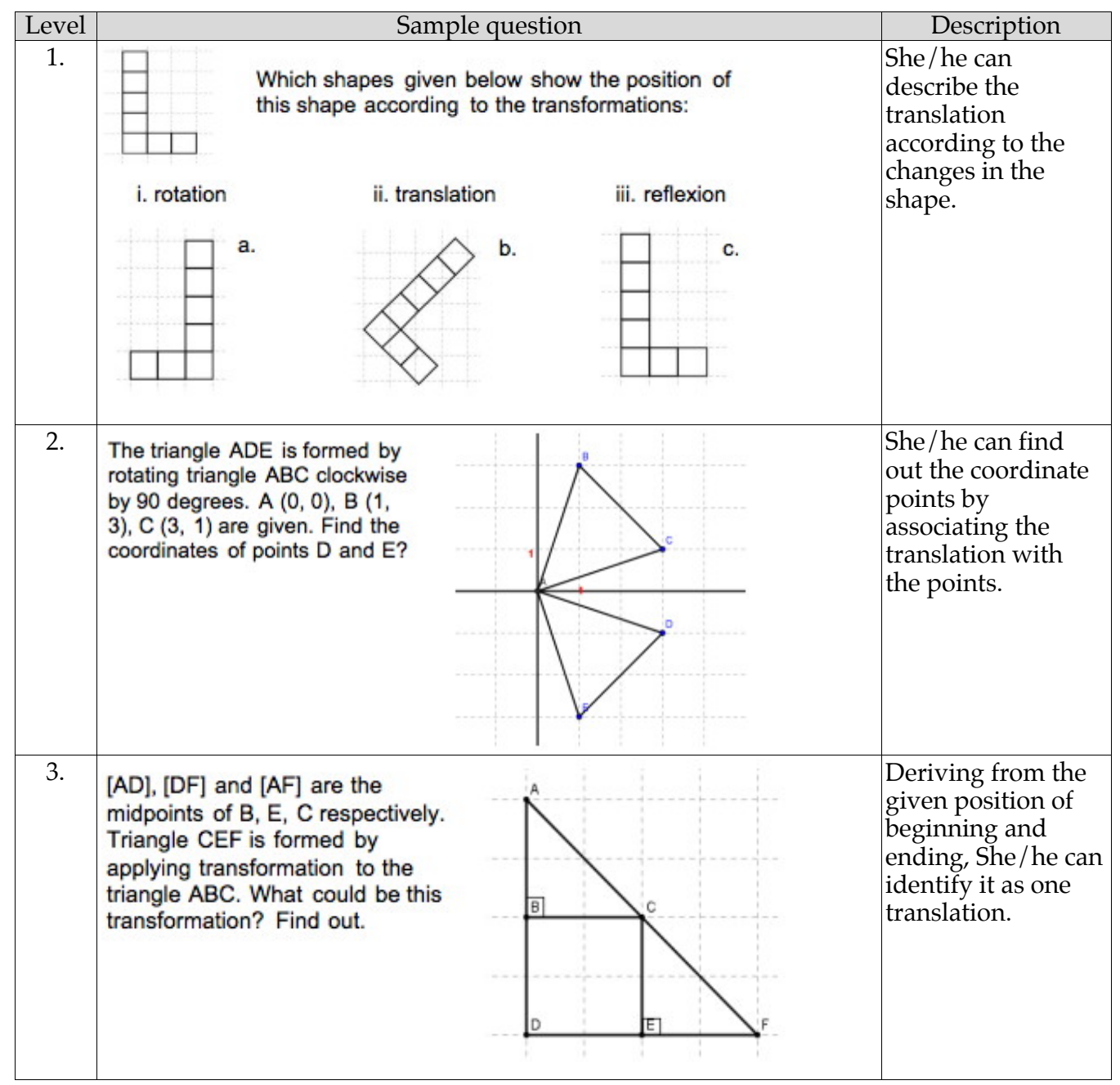

\section{Procedure}

\section{Treatment of the experimental group}

Before the treatment, students in the DGS group were trained on how to use Cabri software since it was new for them. Students learned the functions of the buttons, such as how to draw a line, segment, and form a polygon etc.; how to drag and construct bisectors; and how to measure length, area, angle, etc. The teacher spent four class hours on teaching Cabri. During this four hour period, no application regarding geometric transformations was made with learners. Only technical characteristics and basic use of the software were summarised in the courses. Pre-tests, which were the precautions to prevent this four hour period from becoming a reason for differences between learners, were applied after the phase of introducing the software which lasted for 4 hours. The students in this group used the features of Cabri software to study the worksheets that were handed out for lessons. Also, these students studied 
their own transformations on the computer independently from the worksheets. The dynamic feature of the software enabled students to easily study the different type of transformations and observe the dynamic effects of change on the main object on the image object. For instance, as shown in Figure 1, the students could easily change the angle and rotation point in rotation and observe the effects of the change.
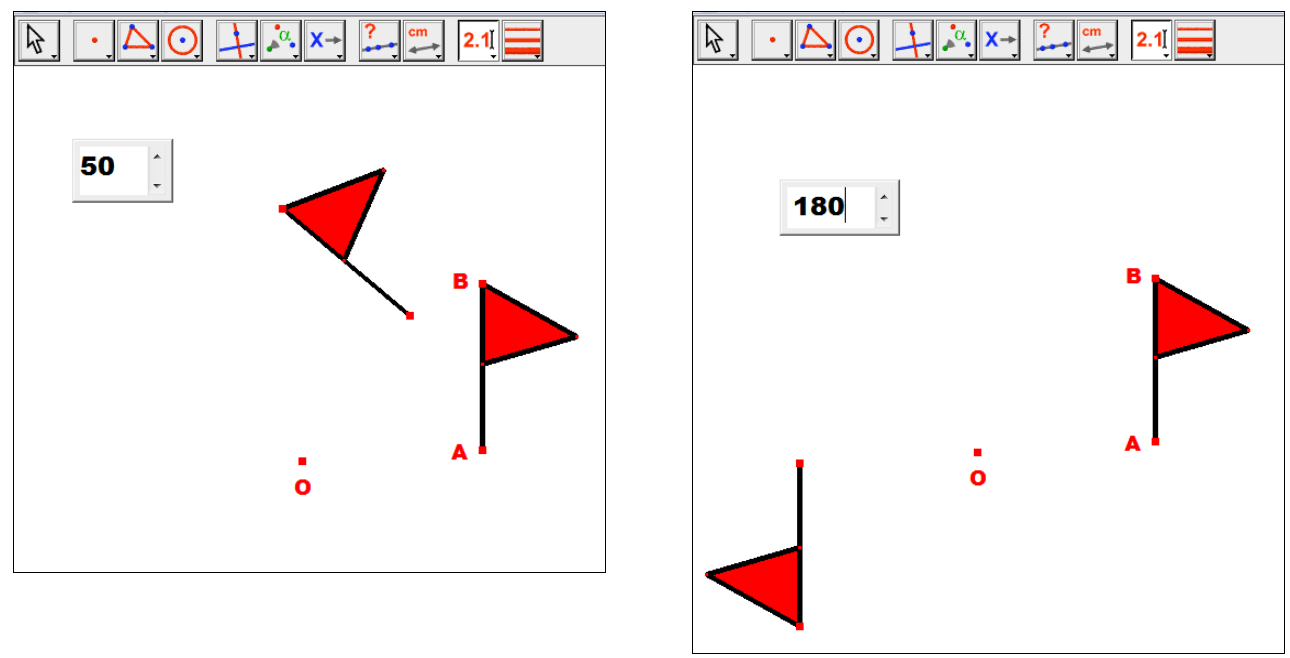

Figure 1: Screen pictures, examples of rotation in DGE

Direct information was not presented on the worksheets which were given to students. The students were supposed to perform transformation applications and observe their effects. Also, they were supposed to write the observation results in the related places on the worksheets. In this group an exploratory approach was followed according to the features of transformation. During the course of application made with experimental group, learners studied in groups with two learners due to the limited number of computers. Generally, during these applications, learners experienced:

- Step by step construction of a transformation in the Cabri environment in accordance with the instructions written on worksheets.

- Dynamic observation of the transformation by dragging geometric objects (e.g. changing symmetry line or point or rotation angle).

- Exploring the characteristics of the transformation, confirmation of the exploration and explanation in the relevant section of the worksheet.

- Discussion of the obtained results in the classroom.

- Making the transformations written in worksheets according to the information obtained after classroom discussion and confirmation with Cabri.

As it is seen, DGS was used as an instrument to explore the characteristics of the transformation, test the discovered characteristics and observe the transformation dynamically over the course of applications. Besides, learners were granted with the opportunity to practise and test what they learnt on computer screen and check their learning accordingly. In this process, the classroom teacher acted primarily as a facilitator with the role of organising the classroom discussions. 
Treatment of the control group

In the transformation geometry application which was conducted with the control group students, mostly dotted, isometric and platting worksheets were used depending on the structure of transformation. The material taught in this group paralleled the material taught in the experimental group, but all activities that were carried out interactively in the computer environment were completed by the control group students using pencil and paper. During the course of applications made with the control group, learners studied in groups with two learners as did experimental group students. Generally during these applications, learners' experiences paralleled the experimental group students:

- Step by step construction of transformation with dotted isometric paper and pencil in accordance with the instructions written on worksheets.

- Exploring the characteristics of the transformation, confirmation of the exploration and explanation in the relevant section of the worksheet.

- Discussion of the obtained results in the classroom.

- Making the transformations with paper and pencil written in worksheets according to the information obtained after classroom discussion.

In order to prevent the teacher from being the source of possible differences between academic achievements and comprehension levels of groups, courses were given by the same teacher to both experimental and control groups. The teacher conducting the research had 6 years of teaching experience and holds a Master of Science degree in mathematics education. Thus, it is possible to say that the teacher was qualified enough to use both DGS and other educational materials, as he had courses about DGS and worksheets in his education. Also, the teacher, who participated voluntarily in the study, was not an author of this research.

Applications lasted for 8 hours in both groups. Of these 8 course hours, 2 hours were for translation and reflection, and 2 hours were for rotation transformations (learners studied these transformations in sixth and seventh grades, in a traditional environment). The remaining 4 hours were reserved for composite transformations, and reflection and translation transformations on analytical plane. Despite the fact that eighth grade students are only responsible for composites of transformations and transformations made on analytical plane, transformations taught in sixth and seventh grades were re-taught, to remind learners about their previous knowledge and to progress this knowledge.

\section{Data analysis}

The TGAT consists of 15 multiple choice questions about transformation. For every correct answer one point and for every wrong or blank answer no point was given, resulting in a possible range of 0 to 15 points.

The LLTGT consists of 15 open ended geometry questions. All participants' answer sheets from LLTGT were read and scored independently by two researchers (one being the author). After the analysis, these researchers together decided upon students' levels of understanding. All participants received a score for each van Hiele level according to Usiskin's (1982) grading system. The criterion for success at any given level was four out of five correct responses. In this study, a student was given or assigned a weighted sum score for LLTGT in the following manner: 
1 point for meeting criteria on items 1-5 (Level-I)

2 points for meeting criteria on items 6-10 (Level-II)

4 points for meeting criteria on items 11-15 (Level-III)

This means that possible range of scores was 0 to 7 points.

The SPSS statistical package program was used to analyse the data obtained from the TGAT and LLTGT scores. Frequency tables were constructed for LLTGT scores to capture detailed information about distributions of participants' Van Hiele levels. An independent sample $t$-test was performed for pre-LLTGT and TGAT scores of the experimental and control groups. In order to observe any significant differences in the post-test scores, a covariance analysis (ANCOVA) controlling for the pre-test was carried out.

\section{Results}

\section{Is there any meaningful difference in the students' TGAT scores?}

As seen in Table 6, the results of an independent $t$-test showed no statistically significant difference in pre-TGAT scores between the experimental group $(M=9.83$, $S D=1.59)$ and the control group $(M=9.18, S D=2.92)[t(66)=1.148, p>.05]$. Therefore this result showed that groups were at the same level in all concepts prior to implementation and thus exhibited comparable characteristics.

Table 6: Descriptive analysis of groups' TGAT scores

\begin{tabular}{|l|c|c|c|c|c|}
\hline \multirow{2}{*}{ Group } & \multirow{2}{*}{$\mathrm{n}$} & \multicolumn{2}{c|}{ Pre-test } & \multicolumn{2}{c|}{ Post-test } \\
\cline { 3 - 6 } & & $M$ & $S D$ & $M$ & $S D$ \\
\hline Experimental & 36 & 9.83 & 1.59 & 13.22 & 2.01 \\
\hline Control & 32 & 9.18 & 2.92 & 11.87 & 2.43 \\
\hline
\end{tabular}

In order to compare the effects of instructional strategies administered to the groups on post-test scores using ANCOVA, a test of homogeneity of within groups regression slopes was conducted. As a result of the analysis, Group * pretest $[F(3,64)=.511, p>$ .05], within groups slopes were found to be homogenous.

Table 7: Results of the covariance analysis of TGAT scores

\begin{tabular}{|c|c|c|c|c|c|c|c|c|}
\hline \multirow{2}{*}{ Variable } & \multicolumn{3}{|c|}{${ }^{*}$ Estimated marginal means for post-test } & \multirow{2}{*}{$\begin{array}{c}\text { Mean } \\
\text { difference }\end{array}$} & \multirow{2}{*}{$d f$} & \multirow[b]{2}{*}{$F$} & \multirow[b]{2}{*}{$p$} & \multirow{2}{*}{$\begin{array}{c}\text { Partial eta } \\
\text { squared }\end{array}$} \\
\hline & Group & $M^{*}$ & Std. error & & & & & \\
\hline TGAT & Experimental & 13.03 & .28 & .946 & $1-64$ & 5.111 & .027 & .073 \\
\hline score & Control & 12.08 & .30 & & & & & \\
\hline
\end{tabular}

The result of the ANCOVA related to TGAT scores indicated significant overall treatment effects, controlling for pretest $[F(1,65)=5.111, p<.05]$. As seen Table 7 , students in the experimental groups benefited significantly more than those in the control groups [mean difference $=.946, p<.05$ ]. Effect sizes calculated were partial eta squared $=.073$. If these effects are evaluated according to Cohen's (1988) interpretations, it can be stated that the DGS-based instruction method had a moderate effect on students' geometry achievement. 


\section{Is there any meaningful difference in students' understanding of transformation geometry levels?}

As seen in Table 8, the results of an independent $t$-test showed no statistically significant difference in pre-test LLTGT scores between the experimental group $(M=$ $2.36, S D=1.97)$ and the control group $(M=2.18, S D=1.92)[t(66)=.366, p>.05]$. Therefore, this result showed that groups were at the same level in all concepts prior to implementation and thus exhibited comparable characteristics.

Table 8: Descriptive analysis of groups related to LLTGT scores

\begin{tabular}{|c|c|c|c|c|c|c|c|c|c|c|c|c|}
\hline \multirow[t]{2}{*}{ Test } & \multirow[t]{2}{*}{ Group } & \multirow[t]{2}{*}{$\mathrm{n}$} & \multicolumn{2}{|c|}{$\begin{array}{c}\text { Not } \\
\text { attained }\end{array}$} & \multicolumn{2}{|c|}{ Level-1 } & \multicolumn{2}{|c|}{ Level-2 } & \multicolumn{2}{|c|}{ Level-3 } & \multicolumn{2}{|c|}{$\begin{array}{c}\text { LLTGT } \\
\text { score }\end{array}$} \\
\hline & & & $f$ & $\%$ & $f$ & $\%$ & $f$ & $\%$ & $f$ & $\%$ & $M$ & $S D$ \\
\hline \multirow[t]{2}{*}{ Pre-test } & Experimental & 36 & 3 & 8.3 & 15 & 41.7 & 14 & 38.9 & 4 & 11.1 & 2.36 & 1.97 \\
\hline & Control & 32 & 4 & 12.5 & 13 & 40.6 & 12 & 37.5 & 3 & 9.4 & 2.18 & 1.91 \\
\hline \multirow[t]{2}{*}{ Post-test } & Experimental & 36 & 0 & 0.0 & 6 & 16.7 & 16 & 44.4 & 14 & 38.9 & 4.22 & 2.35 \\
\hline & Control & 32 & 1 & 3.1 & 8 & 25.0 & 17 & 53.1 & 6 & 18.8 & 2.96 & 1.93 \\
\hline
\end{tabular}

In order to compare the effects of instructional strategies used with the groups on posttest LLTGT scores using ANCOVA, a test of homogeneity of within groups regression slopes was conducted. As a result of the analysis, Group * pretest $[F(3,64)=.023, p>$ .05], within groups slopes were found to be homogenous.

Table 9: The results of the covariance analysis on LLTGT scores

\begin{tabular}{|c|c|c|c|c|c|c|c|c|}
\hline \multirow{2}{*}{ Variable } & \multicolumn{3}{|c|}{ * Estimated marginal means for post-test } & \multirow{2}{*}{$\begin{array}{c}\text { Mean } \\
\text { difference }\end{array}$} & \multirow{2}{*}{$d f$} & \multirow[b]{2}{*}{$F$} & \multirow[b]{2}{*}{$p$} & \multirow{2}{*}{$\begin{array}{l}\text { Partial eta } \\
\text { squared }\end{array}$} \\
\hline & Group & $M^{*}$ & Std. error & & & & & \\
\hline LLTGT & Experimental & 4.151 & .226 & 1.103 & $2-65$ & 11.183 & .001 & .147 \\
\hline score & Control & 3.049 & 240 & & & & & \\
\hline
\end{tabular}

The result of the ANCOVA related to LLTGT scores indicated significant overall treatment effects, controlling for pretest $[F(2,65)=11.183, p<.01]$. As seen Table 9, students in the experimental groups benefited significantly more than those in the control groups [mean difference $=1.103, p<.01$ ]. Effect sizes calculated were partial eta squared $=.147$. If these effects are evaluated according to Cohen's (1988) interpretations, it can be stated that the DGS-based instruction method had a high effect on students' levels of understanding of transformation geometry.

\section{Discussion and conclusions}

In this study, the effect of DGS on the students' academic achievement and their level of understanding of transformation geometry was examined using a quasiexperimental research design.

The results of the TGAT administered to the experimental and control groups at the beginning of the study revealed that there was no meaningful difference in prelearning between the two groups. Administering the same test at the end of the study revealed that there was a significant difference in favor of experimental group. This result shows that DGS has a positive effect on the academic achievement of students. There may be several reasons explaining this effect. The processes of controlling of their own learning pace and carrying out their ideas and actions on a computer screen can positively affect students' learning. In the DGS learning environment students can 
easily change the symmetry lines, symmetry centre points, geometric shapes and rotation angles. They also can observe the effects of the changes on symmetry. This treatment enabled the students to understand and interiorise the nature of change. Moreover, studying transformations designed by themselves without reference to worksheets, choosing and designing the elements necessary for performing a transformation on a computer screen such as screen angle measure and symmetry line, can lead students to develop an advanced understanding of transformation.

The findings of this study are consistent with conclusions reached by Hollebrand (2003), who found that over time the students interiorised the acts they had performed on a computer screen in a study carried out in a technological environment, in which students' understanding of transformation geometry was analysed according to APOS theory. Moreover, Hollebrand (2003) revealed that the acts contributed to students' ability to construct explanations about transformation geometry. However, the students in the control group did not develop dynamic understanding of transformations. Because they did their transformations on isometric and platting worksheets, these students could not observe dynamically multiple instances of how a change of basic elements can cause a change in transformations. For instance, they could not observe directly the change of symmetry. Also, they only examined transformation angle in the change of symmetry, and they performed transformations only on the limited number of samples that were presented to them.

In the present study, the experimental group students could define their mistakes by observing the coherence between the geometric shape they obtained on the computer screen and their expectations before the application. Thus they received feedback from the computer and could discuss this feedback with the classroom teacher. However, the control group students, after designing their transformations on the paper, could decide whether or not their drawings were correct only when they received feedback from their teacher. This case may have an active role on the difference generated in the meaning of achievement. The experimental group's opportunity to generate their own feedback on computer screens may have been a major factor in the difference in achievement between the two groups. Baki et al. (2011) found that using DGS and generating their own feedback made a crucial contribution to pre-service teachers' cognitive development. A similar contribution to younger learners' cognitive development is an implication of this study.

Different research results are reported in the literature on the contributions of DGS learning environments to the development of students' geometric thinking. While some studies have reached the conclusion that DGS has raised the levels of students' geometry understanding (Sang Sook, 1999, Breen, 1999), some have found no important effect (Johnson, 2002; Larew, 1999). However, no previous study has investigated the effect of DGS on students' levels of understanding of transformation geometry. The present study has helped fill this gap by showing that DGS increased eighth grade students' levels of understanding of transformation geometry.

Before the application, the results of the LLTGT showed that the experimental and control group students were primarily in the first and second levels. That is, some students could recognise transformations and had information about some features of transformations. Considering the Turkish elementary mathematics education curriculum, emphasising the features of the transformation, this level of understanding was to be expected. Before the application, very few students were in the third level, indicating that the great majority could not apply combinations of transformations, 
make connections between transformations, and associate transformations with coordinates. After the application, 38.9\% of the students in the experimental group had reached the third level (from $11.1 \%$ to $38.9 \%$ ), while the number of students at the first level decreased markedly (from $41.7 \%$ to $16.7 \%$ ) and almost half were in the second level $(44.4 \%)$. This finding demonstrates that the DGS application had a positive effect on the experimental group's levels of understanding of transformation geometry. On the computer, the experimental group students were able to make many different transformations on the same geometric shape in succession. This observation indicates that many students increased their competence in understanding combinations of transformations and making connections between transformations. In addition, the opportunity to observe dynamically the features of geometric transformations in an exploratory environment increased students' understanding of these features.

As the outcomes from this study show, a curriculum enriched by DGS can significantly improve not only the academic success of students but also their levels of understanding of transformation geometry. Hence, mathematics teachers should be encouraged to use this software in their classes. After this experimental study, informal interviews with the teacher of experimental and control groups in this study showed that the teacher continued to use DGS actively in his different courses for different topics in the 2010-2011 academic year. Towards this end, teachers should be introduced to the software in pre-service and in-service courses, in order to experience its effects on their own learning, and educated in the design of computer-based mathematics learning environments. We further recommend qualitative research to investigate in depth the roots and causes of the effects obtained in this study.

\section{References}

Aarnes, J. \& Knudtzon, S. (2003). Conjecture and discovery in geometry: A dialogue between exploring with dynamic geometric software and mathematical reasoning. Matematiska och Systemtekniska Institutionen. http:/ / vxu.se/msi/ picme10/f5aj.pdf

Baki, A., Kösa, T. \& Güven, B. (2011). A comparative study of the effects of using dynamic geometry software and physical manipulatives on the spatial visualisation skills of preservice mathematics teachers. British Journal of Educational Technology, 42(2), 291-310. http: / / dx.doi.org/10.1111/j.1467-8535.2009.01012.x

Battista, M. T. (2007). The development of geometric and spatial thinking. In F. K. Lester (Ed.), Second handbook of research on mathematics teaching and learning (pp. 843-908). Charlotte, NC: Information Age Publishing.

Botana, F. \& Valcarce, J. L. (2003). A software tool for the investigation of plane loci. Mathematics and Computers in Simulation, 61(2), 139-152. http: / / dx.doi.org/10.1016/S0378-4754(02)00173-8

Breen, J. J. (1999). Achievement of van Hiele level two in geometry thinking by eight grade students through the use of geometry computer-based guided instruction. Unpublished Doctoral Dissertation, The University of South Dakota.

Carraher, D. W. \& Schliemann, A. D. (2007). Early algebra and algebraic reasoning. In F. K. Lester (Ed.), Second handbook of research on mathematics teaching and learning (pp. 669-705). Charlotte, NC: Information Age Publishing.

Christou, C., Mousolides, N., Pittalis, M. \& Pitta-Pantazi, D. (2005). Problem solving and problem posing in a dynamic geometry environment. The Montana Mathematics Enthusiast, 2(2), 125-143. http: / / www.math.umt.edu/tmme/vol2no2/tmmev2n2a5.pdf 
Clements, D. H. \& Burns, B. A. (2000). Students' development of strategies for turn and angle measure. Educational Studies in Mathematics, 41(1), 31-45. http: / / dx.doi.org/10.1023/ A:1003938415559

Cohen, J. (1988). Statistical power analysis for the behavioral sciences (2nd ed.). New Jersey: Lawrence Erlbaum.

Crowley, M. (1987). The van Hiele model of development of geometric thought. In M. M. Lindquist \& A. P. Shulte (Eds.), Learning and teaching geometry, K-12. 1987 Yearbook of the National Council of Teacher of Mathematics (pp. 1-16), Reston: Va.

Dixon, J. K. (1997). Computer use and visualization in students' construction of reflection and rotation concepts. School Science and Mathematics, 97(7), 352-358. http: / / dx.doi.org/10.1111/j.1949-8594.1997.tb17376.x

Edwards, L. (1990). Children's learning in a computer microworld for transformation geometry. Unpublished doctoral dissertation, University of California, Berkeley.

Edwards, L. \& Zazkis, R. (1993). Transformation geometry: Naïve ideas and formal embodiments. Journal of Computers in Mathematics and Science Teaching, 12(2), 121-145.

Edwards, L. (1992). A comparison of children's learning in two interactive computer environments. Journal of Mathematical Behavior, 11(1), 73-81. http: / / www.eric.ed.gov / ERICWebPortal/ detail?accno=EJ450647

Edwards, L. (1997). Exploring the territory before proof: Students' generalizations in a computer microworld for transformation geometry. International Journal of Computers for Mathematical Learning, 2(3), 187-215. http:/ / dx.doi.org/10.1023/A:1009711521492

Erbas, A. K. \& Yenmez, A. A. (2011). The effect of inquiry-based explorations in a dynamic geometry environment on sixth grade students' achievements in polygons. Computers $\mathcal{E}$ Education, 57(4), 2462-2475. http:/ / dx.doi.org/10.1016/j.compedu.2011.07.002

Fuys, D., Geddes, D. \& Tischler, R. (1988). The van Hiele model of thinking in geometry among adolescents. Journal for Research in Mathematics Education, Monograph Vol 3. NCTM. http: / / www.jstor.org/ stable/ 749957

Guven, B., Cakiroglu, U. \& Akkan, A. (2009). The gap between expectations and reality: Integrating computers into mathematics classrooms. Asia Pacific Education Review, 10(4), 505515. http: / / dx.doi.org/10.1007/s12564-009-9047-7

Habre, S. (2009). Geometric conjectures in a dynamic geometry software environment. Mathematics and Computer Education, 43(2), 151.

Harper, S. R. (2002). Enhancing elementary pre-service teachers' knowledge of geometric transformations. Unpublished Doctoral Dissertation, University of Virginia.

Hollebrands, K. F. (2003). High school students' understanding of geometric transformations in the context of a technological environment. Journal of Mathematical Behavior, 22, 55-72. http: / / dx.doi.org/10.1016/S0732-3123(03)00004-X

Hoyles, C. \& Jones, K. (1998). Proof in dynamic geometry contexts. In C. Mammana \& V. Villani (Eds.), Perspectives on the teaching of geometry for the 21st century (pp. 121-128). Dordrecht: Kluwer Academic Publishers. http: / / eprints.soton.ac.uk/41227/1/Hoyles_Jones_proof_DGS_1998.pdf

Johnson, C. D. (2002). The effects of the Geometer's Sketchpad on the van Hiele levels and academic achievement of high school students. Unpublished doctoral dissertation, Wayne State University, Detroit, Michigan. http: / / digitalcommons.wayne.edu / dissertations / AAI3071795/

Johnson-Gentile, K., Clements, D. \& Battista, M. (1994). Effects of computer and noncomputer environments on students' conceptualizations of geometric motions. Journal of Educational Computing Research, 11(2), 121-141. http:/ / dx.doi.org/10.2190/49EE-8PXL-YY8C-A923 
Larew, L. W. (1999). The effects of learning geometry using a computer-generated automatic draw tool on the levels of reasoning of college developmental students. Unpublished Doctoral Dissertation, West Virginia University.

Luthuli, D. (1996). Questions, reflection, and problem solving as sources of inquiry in Euclidean geometry. Pythagoras, 40, 17-27.

Marrades, R. \& Gutiérrez, A. (2000). Proofs produced by secondary school students learning geometry in a dynamic computer environment. Educational Studies in Mathematics, 44 (1-3), 87-125. http: / / dx.doi.org/10.1023 / A:1012785106627

McCoy, L. (1991). The effects of geometry tool software on high school geometry achievement. Journal of Computers in Mathematics and Science Teaching, 10, 51-57.

NCTM (National Council of Teachers of Mathematics) (2000). Principles and standards for school mathematics: Electronic examples. [viewed 11 Aug 2010]. http:/ / standardstrial.nctm.org/ document/ eexamples/chap6/6.4/index.htm

Olson, M., Zenigami, F. \& Okazaki, C. (2008). Students' geometric thinking about rotations and benchmark angles. Mathematics Teaching in the Middle School, 14, 24-26. http: / / www.nctm.org/publications / article.aspx?id=20780

Peterson, J. C. (1973). Informal geometry in grades 7-14. In K.B. Henderson (Ed.), Geometry in the mathematics curriculum: Thirty-sixth yearbook. (pp. 52-91).Washington, DC: NCTM. http: / / www.eric.ed.gov / ERICWebPortal/ detail?accno=EJ090197

Rollick, M. B. (2009). Toward a definition of reflection. Mathematics Teaching in the Middle School, 14(7), 396-398. http: / / www.nctm.org/eresources/view_media.asp?article_id=8696

Sang Sook, C. (1999). A student's learning of geometry using the computer. Journal of Educational Research, 92(5), 301-311. http: / / dx.doi.org/10.1080/00220679909597611

Sinclair, K. J., Renshaw, C. E. \& Taylor, H. A. (2004). Improving computer assisted instruction in teaching higher-order skills. Computers $\mathcal{E}$ Education, 42(2), 169-180. http: / / dx.doi.org/10.1016/S0360-1315(03)00070-8

Soon, Y. (1989). An investigation of van Hiele-like levels of learning in transformation geometry of secondary school students in Singapore. Unpublished Doctoral Dissertation, The Florida State University.

Stols, G. \& Kriek, J. (2011). Why don't all maths teachers use dynamic geometry software in their classroom? Australasian Journal of Educational Technology, 27(1), 137-151. http: / / www.ascilite.org.au/ajet/ajet27/stols.html

TTKB (2004). Ilkögretim Matematik Dersi (1.-5. siniflar) Ögretim Programi. Ankara: MEB Talim Terbiye Kurulu Baskanligi Yayinlari.

http: / / ttkb.meb.gov.tr/ program.aspx?islem $=1 \& k n o=32$

Usiskin, Z. (1982). Van Hiele levels and achievement in secondary school geometry. Final report of the CDASSG Project. Chicago: University of Chicago. (ERIC Document Reproduction Service No. ED220288). [verified 10 Mar 2012; 1.9 MB] http: / / www.eric.ed.gov/ERICWebPortal / contentdelivery/ servlet/ERICServlet?accno=ED220288

Author: Associate Professor Dr Bulent Guven

Department of Secondary School Science and Mathematics Education, Fatih Faculty of Education, Karadeniz Technical University, Sogutlu, Akcaabat, Trabzon, Turkey Email: bguvenktu.edu.tr, guvenbulent@gmail.com

Please cite as: Guven, B. (2012). Using dynamic geometry software to improve eight grade students' understanding of transformation geometry. Australasian Journal of Educational Technology, 28(2), 364-382.

http: / / www.ascilite.org.au/ajet/ajet28/guven.html 